\title{
Etomidate Shows Prospect as an Anti-Arrhythmic Drug Conferring Safe Sedation and Sinus Conversion Simultaneously
}

\author{
Maryam Saif Al Ali ${ }^{a} \quad$ Anas Musab ${ }^{b}$ Wael Hamadeh ${ }^{a} \quad$ Esam Seddik $^{c}$ \\ aEmergency Department, Rashid Hospital Trauma Center, Dubai Health Authority, Dubai, United Arab Emirates; \\ ${ }^{b}$ Cardiology Department, Rashid Hospital Trauma Center, Dubai Health Authority, Dubai, United Arab Emirates; \\ 'Anesthesia Department, Rashid Hospital Trauma Center, Dubai Health Authority, Dubai, United Arab Emirates
}

\section{Keywords}

Etomidate $\cdot$ Anti-arrhythmic drug $\cdot$ Ventricular tachycardia .

Supraventricular tachycardia

\begin{abstract}
This case is of a 76-year-old man with a known history of hypertension, type 2 diabetes mellitus, and ischemic heart disease, who presented to our department with chest pain and palpitations. His electrocardiogram showed a ventricular tachycardia (VT), but fortunately our patient was hemodynamically stable. A trial of adenosine was given to convert the patient's heart back to sinus rhythm, but was unsuccessful and the rhythm remained as VT. Soon after, the patient suddenly became hemodynamically unstable as his blood pressure acutely declined; thus, the decision to perform a direct current cardioversion was taken. Bearing in mind that the patient was still awake, he was given $10 \mathrm{mg}$ of intravenous etomidate as a pre-procedural sedative. During the time it took to prepare for the procedure, the patient's rhythm reverted from VT to a regular sinus rhythm, raising his blood pressure back to normal and achieving hemodynamic stablility, negating the need of any electrical or chemical cardioversion. Our patient was then handed over to the cardiology team for an emergency percutaneous coronary intervention procedure and an implantable cardioverter-defibrillator procedure, both of which were successful. Etomi-
\end{abstract}

date was used in this case for the purpose of sedation, and as luck would have it, it seems that it had also incidentally reverted the arrhythmia back to normal.

(C) 2020 The Author(s).

Published by S. Karger AG, Basel

\section{Introduction}

Etomidate has a good safety profile for sedating patients prior to an emergency cardioversion, especially if they are hemodynamically unstable and there is not enough time to use the conventional agents of chemical cardioversion, such as amiodarone, for such cases of wide complex ventricular tachycardia (VT) in the setting of an acute myocardial ischemia. There are a lot of sedative options generally available in the emergency department as premedication before cardioversion. Etomidate and propofol both possess properties to convert arrhythmias back to sinus rhythms, which make them superior choices in sedating patients with arrhythmias. Etomidate has an atrioventricular (AV) blocking effect on the heart, which could be attributed to its property to revert a VT to a sinus rhythm. This case highlights the emerging importance and versatility of etomidate's anti-arrhythmic quality, in addition to its main sedative purpose. karger@karger.com www.karger.com/dmj

Karger $\stackrel{\text { ' }}{5}$

BOPEN ACCESS
(C) 2020 The Author(s)

Published by S. Karger AG, Basel

This article is licensed under the Creative Commons AttributionNonCommercial-NoDerivatives 4.0 International License (CC BYNC-ND) (http://www.karger.com/Services/OpenAccessLicense) Usage and distribution for commercial purposes as well as any distribution of modified material requires written permission.
Maryam Saif Al Ali

Emergency Department, Rashid Hospital Trauma Center, Dubai Heath Authority PO Box-454

Dubai (United Arab Emirates)

Maryamsaif86@gmail.com 


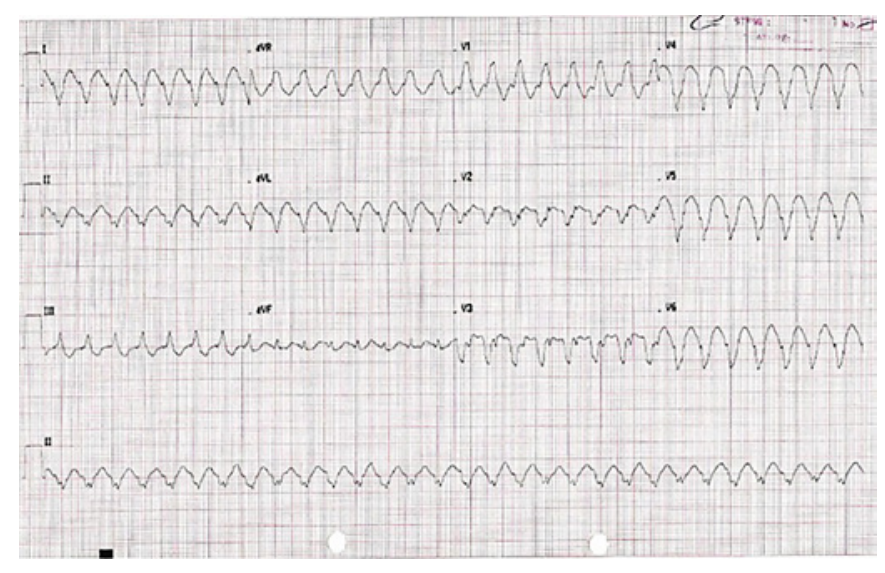

Fig. 1. ECG showing VT with RBBB pattern and positive concordance in inferior leads and extreme right axis deviation. VT, ventricular tachycardia; ECG, electrocardiogram.

\section{Case Report/Case Presentation}

A 76-year-old man, with known case of hypertension, type 2 diabetes mellitus, dyslipidemia, and ischemic heart disease, with additional history of having undergone a percutaneous coronary intervention in the past, presented to our emergency department complaining of sudden onset chest pain and palpitations. The patient did not complain of any shortness of breath, denied having any syncopal attacks or loss of consciousness, and had no recent nausea, vomiting, dizziness, or sweating.

On examination, the patient was fully conscious and oriented to time, place, and person, with a Glasgow Coma Scale (GCS) of $15 / 15$. His blood pressure was $105 / 80 \mathrm{~mm} \mathrm{Hg}$ and heart rate was 185 beats/min. Oxygen saturation at room air was $98 \%$.

Auscultation of his chest revealed good air entry, equal bilaterally, with bibasilar crackles. Other than the tachycardia, his heart sounds were normal with no murmurs. Peripheral pulses were palpable in all four limbs, with no pitting edema present. The rest of the patient's examination was unremarkable, without any focal neurological deficit.

\section{Investigations}

White blood count was $5.5 \times 10^{3}$, hemoglobin was 12.6 $\mathrm{g} / \mathrm{dL}$, and platelet count was $179 \times 10^{3}$. Cardiac pro-BNB was $232.3 \mathrm{pg} / \mathrm{mL}$. Troponins rose from 0.02 to $1.60 \mathrm{ng} /$ $\mathrm{mL}$. Random blood glucose was $168 \mathrm{mg} / \mathrm{dL}$ and hemoglobin A1C was $7.2 \%$. The lipid profile showed total cholesterol of $136 \mathrm{mg} / \mathrm{dL}$, triglycerides of $90 \mathrm{mg} / \mathrm{dL}$, high-density lipoprotein of $44 \mathrm{mg} / \mathrm{dL}$, and low-density lipoprotein of $86 \mathrm{mg} / \mathrm{dL}$. Prothrombin time was $13.2 \mathrm{~s}$, activated partial thromboplastin time was $27.8 \mathrm{~s}$, and international normalized ratio was 1.0. His potassium was $3.6 \mathrm{mg} / \mathrm{dL}$, sodium was $135 \mathrm{mg} / \mathrm{dL}$, blood urea was $42 \mathrm{mg} / \mathrm{dL}$, and serum calcium was $8.9 \mathrm{mg} / \mathrm{dL}$. Thyroid stimulating hormone was $1.23 \mu \mathrm{IU} / \mathrm{mL}$.

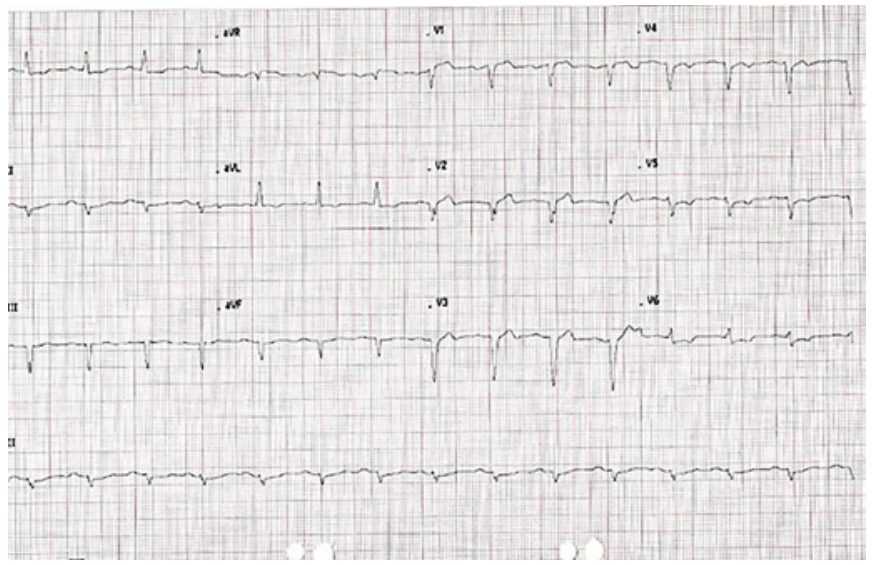

Fig. 2. ECG after etomidate reverted to sinus rhythm, with ST segment depression and T-inversion in V4-6. ECG, electrocardiogram.

A chest X-ray was performed and reported to be normal as per the patient's baseline. An electrocardiogram was performed and revealed a wide complex tachycardia, thus diagnosing it as VT (Fig. 1).

\section{Differential Diagnosis}

Differential diagnosis revealed VT secondary to acute coronary syndrome, VT due to myocardium scarring, fascicular VT, and supraventricular tachycardia (SVT) with aberrancy.

\section{Treatment}

The patient was immediately shifted to the resuscitation room and was attached to the cardiac monitor. An intravenous (IV) line was established and $0.9 \%$ normal saline infusion was started. Seeing that the patient was hemodynamically stable and had a monomorphic VT, a trial of adenosine $6 \mathrm{mg}$ IV was given, but had no effect on the patient's heart rate and rhythm.

A few minutes later, the patient's blood pressure dropped to $80 / 55 \mathrm{~mm} \mathrm{Hg}$ and became hemodynamically unstable. A bolus of etomidate $10 \mathrm{mg}$ IV was given in preparation for an electrical cardioversion. Two minutes after, the patient's rhythm reverted back to sinus rhythm with a heart rate of 88 beats/min and a blood pressure of 110/79 $\mathrm{mm} \mathrm{Hg}$, before any shock was given (Fig. 2).

He was admitted under the cardiology team and was then taken to the coronary catheterization laboratory where they performed a percutaneous coronary intervention to the left anterior descending coronary artery (Fig. 3, $4)$. 


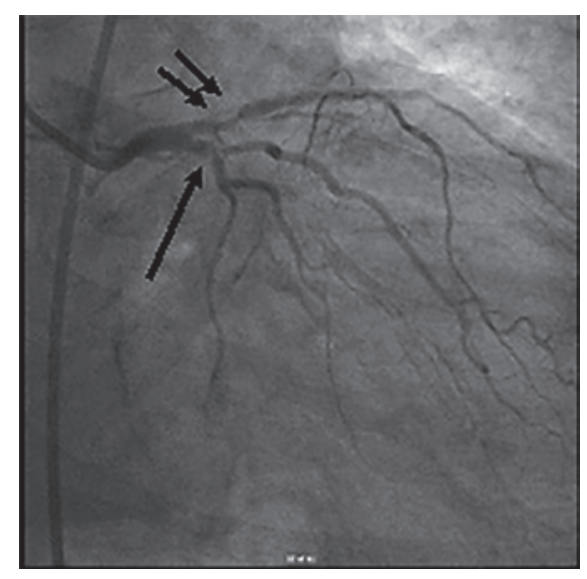

Fig. 3. CAG showing LAD (short arrows) and LCx (long arrow) lesions. CAG, coronary angiogram; LAD, left anterior descending coronary artery.

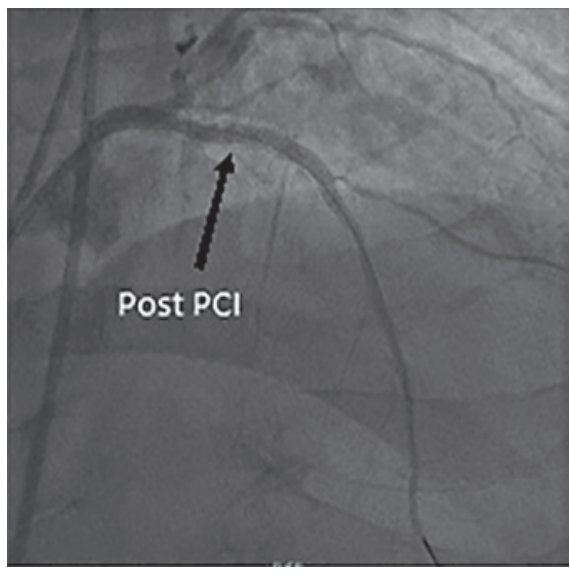

Fig. 4. Post-stenting of LAD (arrow) with 1 drug-eluting stent. LAD, left anterior descending coronary artery.

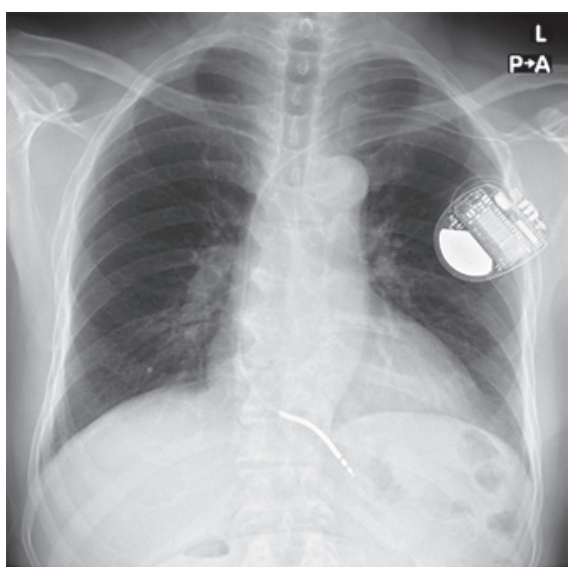

Fig. 5. Chest X-ray with ICD in place. ICD, implantable cardioverter-defibrillator.

\section{Outcome and Follow-Up}

Fortunately, the patient's rhythm remained regular and sinus, so he did not require any kind of electrical cardioversion or chemical cardioversion with amiodarone. In view of the echocardiographic findings, biochemical and clinical evidence of an acute coronary syndrome, the patient was handed over to the cardiology department for a coronary angiography and stenting of the left anterior descending coronary artery, as well as an insertion of an implantable cardioverter-defibrillator (ICD). Both procedures went well without any further complications (Fig. 5). The patient remained stable throughout his stay and after his discharge without any kind of ischemic heart symptoms. Interrogation of the implanted implantable cardioverter-defibrillator showed no recorded episodes of VT.

\section{Discussion}

Etomidate is an imidazole derivative that has been in use since the year 1972. It has an activity profile that is similar to that of thiopental, with rapid onset, rapid peak activity, and brief duration, but it is remarkable in its lack of adverse hemodynamic effects [1]. The hemodynamic stability seen with etomidate is caused by its lack of effect on the sympathetic nervous system and on the function of the baroreceptor [2]. It has emerged as the agent of choice for emergency department Rapid Sequence Intubation as numerous reports attest to its effectiveness and safety [3].

The anti-arrhythmic property of etomidate came to practice when 2 cases were published highlighting this specific effect. The first case reported in 2005 was that of a 59-year-old patient who had stable SVT, which had failed to revert to a sinus rhythm after a trial of amiodarone and adenosine, after which the patient had developed wide complex tachycardia (VT) and hypotension. Seeing that the patient was unstable, $14 \mathrm{mg}$ of etomidate was given for sedation before electrical cardioversion, and luckily the patient converted to sinus rhythm before the electrical cardioversion was ever given [4].

The second case reported in 2007 was that of a 33-yearold patient with a known history of hypertension, taking atenolol and captopril, presented to the emergency department complaining of palpitations and diaphoresis for the past 45-60 $\mathrm{min}$. The patient stated that he had experienced a similar episode a couple of days ago that lasted around $3 \mathrm{~min}$. In the emergency department, the patient was attached to the cardiac monitor, which demonstrated a wide complex tachycardia that was confirmed with a 12-lead electrocardiogram. The patient subsequently became hemodynamically unstable and $10 \mathrm{mg}$ of etomidate was given for sedation prior to electrical cardioversion. After administration of etomidate, the patient converted to a sinus rhythm before needing any electrical cardioversion [5].

In our case, the patient similarly reverted to sinus rhythm after giving etomidate, making this the third case being reported for the anti-arrhythmic property of etomidate converting VT to sinus rhythm. This anti-arrhythmic effect may be related to its AV blocking effect on the heart, which can be seen in another case of a 79-year-old woman with a psychiatric illness, who was undergoing an electro- 
convulsive therapy, and had subsequently developed severe transient bradycardia with transient complete heart block as soon as she was treated by etomidate during the induction phase of the anesthesia [6]. A similar blocking effect was reported by Van Den et al. [7]. Although its occurrence is rare, this AV blocking effect of etomidate can lead to generation of ventricular fibrillation, as reported by Murat Karcioglua et al. [8] in a 56-year-old woman undergoing a laparoscopic cholecystectomy.

Propofol is another sedative agent frequently used in the emergency department. It has a known negative side effect of hypotension that makes it unsuitable as a first choice for some cardiac patients, especially if they are hemodynamically unstable. Reports have shown wide ranges of converting cardiac arrhythmia to sinus rhythm. Of the reports, atrial fibrillation [9], SVT [10], and VT [11] are reported to be converted to sinus rhythm following propofol administration, with the latter being the least frequently reported. An experimental animal study was performed on a guinea pig's myocardium tissue to observe the electrophysiological effects of racemic ketamine and etomidate in simulated ischemia. The findings showed that ketamine had decreased the ischemia-inducing action potential and dispersion, as well as reperfusion-induced ventricular arrhythmias, whereas etomidate did not have any effect at all [12].

\section{Conclusion}

Etomidate has a good safety profile for sedating patients prior to performing a cardioversion, especially if the rhythm shows a wide complex tachycardia and VT.
There are different options in the emergency department for sedation prior to cardioversion. A good background knowledge of the medication property is essential in deciding the best option in sedating a patient with arrhythmias.

\section{Acknowledgements}

We thank the patient for allowing us to share his medical information for the purpose of this study.

\section{Statement of Ethics}

Written and signed consent have been taken from the patient.

\section{Conflict of Interest Statement}

The authors have no conflicts of interest to declare.

\section{Funding Sources}

No funding was received for this study.

\section{Author Contributions}

M.A.: manuscript preparation, literature search, and review. A.M.: case presentation, literature search, manuscript preparation, and review. W.H.: case presentation and manuscript review. E.S.: case presentation, manuscript review, and literature search.

\section{References}

1 Weiss-Bloom LJ, Reich DL. Haemodynamic responses to tracheal intubation following etomidate and fentanyl for anaesthetic induction. Can J Anaesth. 1992;39(8):780-5.

2 Ebert TJ, Hall JE, Barney JA, Uhrich TD, Colinco MD. The effects of increasing plasma concentrations of dexmedetomidine in humans. Anesthesiology. 2000;93(2):382-94.

3 Sivilotti ML, Filbin MR, Murray HE, Slasor P, Walls RM. Does the sedative agent facilitate emergency rapid sequence intubation? Acad Emerg Med. 2003;10(6):612-20.

4 King S, Banker D. Etomidate as an antiarrhythmic. Br J Anaesth. 2005;95(3):425.

5 Rivera-Bou WL, Torres-Galarza F, Deynes S. Can etomidate have antiarrhythmic properties? Bol Asoc Med P R. 2007 Oct-Dec;99(4): $310-3$.
6 Combeer A. Complete atrioventricular block following etomidate. Eur J Anaesthesiol. 2007;24(12):1067-8.

7 Van den Hurk AW, Teijen HJ. Cardiac complications during use of etomidate. Anaesthesia. 1983;38(12):1183-4.

8 Karcioglua M, Davarcia I, Kireccia N, Akcayb $A B$, Turhanoglua S, Tuzcua K, et al. The development of ventricular fibrillation due to etomidate for anesthetic induction: a very rare side effect, case report. Rev Bras Anestesiol. 2014;64(5):365-8.
9 Òscar Miró MD, Gloria de la Red MD, Jaume Fontanals MD. Cessation of paroxysmal atrial fibrillation during acute intravenous propofol administration. Anesthesiology. 2000;92:910.

10 Kannan S, Sherwood N. Termination of supraventricular tachycardia by propofol. Br J Anaesth. 2002;88(6):874-5.

11 Morgan-Hughes NJ, Heames RM, Hack H, Kannan S, Sherwood N. Propofol as an antiarrhythmic. Br J Anaesth. 2002;89(5):798-9.

12 Hanouz JL, Repesse Y, Zhu L, Lemoine S, Rouet R, Sallé L, et al. The electrophysiological effects of racemic ketamine and etomidate in an in vitro model of "border zone" between normal and ischemic/reperfused guinea pig myocardium. Anesth Analg. 2008;106(2): $365-70$. 